\title{
AUMC Infinity Predicted Normalized by Body Mass Index
}

National Cancer Institute

\section{Source}

National Cancer Institute. AUMC Infinity Predicted Normalized by Body Mass Index. NCI

Thesaurus. Code C92334.

The area under the first moment curve (AUMC) extrapolated to infinity, based on the last predicted concentration divided by the body mass index. 